\title{
Pistacia atlantica Resin Has a Dose-Dependent Effect on Angiogenesis and Skin Burn Wound Healing in Rat
}

\author{
Faraidoon Haghdoost, ${ }^{1}$ Mohammad Mehdi Baradaran Mahdavi, ${ }^{1}$ Alireza Zandifar, ${ }^{1,2}$ \\ Mohammad Hossein Sanei, ${ }^{3}$ Behzad Zolfaghari, ${ }^{4}$ and Shaghayegh Haghjooy Javanmard ${ }^{2}$ \\ ${ }^{1}$ Medical Students' Research Center, Isfahan University of Medical Sciences, Isfahan 81745-319, Iran \\ ${ }^{2}$ Physiology Research Centre, Department of Physiology, Isfahan University of Medical Sciences, Isfahan 81745-319, Iran \\ ${ }^{3}$ Department of Pathology, Isfahan University of Medical Sceinces, Isfahan 81745-319, Iran \\ ${ }^{4}$ Department of Pharmacognosy and Isfahan Pharmaceutical Sciences Research Center, School of Pharmacy, \\ Isfahan University of Medical Sciences, Hezar Jarib Avenue, Isfahan 81745-319, Iran
}

Correspondence should be addressed to Behzad Zolfaghari; behzadz@gmail.com and

Shaghayegh Haghjooy Javanmard; shaghayeghhaghjoo@yahoo.com

Received 20 June 2013; Revised 7 September 2013; Accepted 14 September 2013

Academic Editor: Angelo Antonio Izzo

Copyright (C) 2013 Faraidoon Haghdoost et al. This is an open access article distributed under the Creative Commons Attribution License, which permits unrestricted use, distribution, and reproduction in any medium, provided the original work is properly cited.

Objectives. The aim of the present study was to evaluate the effect of Pistacia atlantica resin extract on the rat skin burn wound healing. Methods. Thirty-two Wistar rats were divided into four groups and treated by vehicle, 5\%, 10\%, and 20\% concentration of Pistacia atlantica resin extract for 14 days (G1, G2, G3, and G4, resp.). The efficacy of treatment was assessed based on reduction of burn wound size and histological and molecular characteristics. Results. $\alpha$-Pinene (46.57\%) was the main content of essential oil of resin. There were no statistically significant differences between groups according to wound size analysis. The mean histological wound healing scores were not statistically different. Capillary counts of G2 and G3 were significantly higher than those of the G1 $(P=0.042$ and 0.032 , resp.). NO concentration in wound fluids on the 5 th day of study was not significantly different between groups $(P=0.468)$. But bFGF concentration in G2 and G3 and PDGF concentration in G3 were significantly higher in comparison to $\mathrm{Gl}(P=0.043,0.017$, and 0.019 , resp.). Conclusion. Our results revealed that Pistacia atlantica resin extract has a concentrationdependent effect on the healing of burn wounds after 14 days of treatment by increasing the concentration of bFGF and PDGF and also through improving the angiogenesis.

\section{Introduction}

Since ancient times, plants have played a major role in the treatment of many diseases, especially in the eastern countries. There are documents showing that Persians were pioneers in using plants for medical purposes. There are 7500-8000 plant species in Iran [1]. Pistacia (Persian name: Bane) is a genus of the family Anacardiaceae. Among 15 known species of pistachios, only some species grow in Iran, such as Pistacia vera L., Pistacia khinjuk Stocks, and Pistacia atlantica Desf. These have played an important role in folk medicine and have been used in treatment of eczema, throat infection, renal stone, and asthma. They also act as astringent, anti-inflammatory, antipyretic, antibacterial, antiviral, pectoral, and stimulant [2].

Pistacia atlantica is a plant native to a number of countries such as Iran, Iraq, and Turkey. The oleoresin of this plant is used for making chewing gum in Iran and has also been used traditionally in the treatment of peptic ulcer disease and as a mouth freshener [3]. This plant's extract is also used traditionally as a wound dressing in Kurdistan of Iran [4].

Millions of people suffer from burn-related disabilities and disfigurements which impose psychological, social, and economic burdens on both burn survivors and their families. In 2002,330,000 deaths were estimated, directly or indirectly, related to burn injury $[5,6]$. Burn wound healing is a critical 
component of the burn patients' successful recovery that is associated with large impact on health care costs $[7,8]$.

Wound healing is a well-ordered response to injury starting with inflammation dominated early phase, progressing to the repair and remodeling of wound tissue. There are three phases in the wound healing process: inflammation, proliferation, and remodeling [9]. The inflammatory phase involves release of cytokines and growth factors, influx of neutrophils and macrophages and creation of an initial matrix [10]. The proliferation phase is characterized by angiogenesis, collagen deposition, reepithelialization, and wound contraction. Endothelial cells initiate angiogenesis and fibroblasts exert collagen and fibronectin to form new extracellular matrix in granulation tissue $[11,12]$. The final phase is matrix remodeling that is characterized through collagen deposition by fibroblasts and formation of an organized network [13]. The complex process of wound healing is regulated by signaling network that involves numerous cytokines, chemokines, and growth factors such as platelet derived growth factor (PDGF) and fibroblast growth factor (FGF) that have been reported to accelerate various aspects of wound healing $[14,15]$.

PDGF is a potent mitogen for all mesenchymal cells and acts as a chemoattractant for neutrophils, monocytes, and fibroblasts. It also stimulates synthesis of fibronectin, glycosaminoglycan, and collagenase [15-18]. Fibroblast growth factors (FGFs) are a family of structurally related polypeptides which are mitogenic for an extensive range of cell types. Basic fibroblast growth factor (bFGF) is a growth factor of FGF family which induces DNA synthesis and angiogenesis, stimulates extracellular matrix formation, and down-regulates collagen type one synthesis [17, 19].

In normal body condition, there is a balance between free radicals and natural scavengers. But during the traumatic state the balance is lost and reactive oxygen species (ROSs) are superior in number. Burn trauma not only up-regulates free radical production but also impairs antioxidant defense mechanism, rendering burn patients more susceptible to ROS-mediated injury through cellular DNA and protein damage $[20,21]$. Nitric oxide (NO) is an intercellular signaling molecule that the efficiently balanced production of it plays an important role in burn healing. The highly valuable effect of bioavailable $\mathrm{NO}$ is ascribed to scavenging of superoxide, as the major component of oxidative stress. NO has also beneficial effect on angiogenesis, inflammation, matrix deposition, and remodeling $[22,23]$.

To the best of our knowledge, there is no previous report on wound healing properties of Pistacia atlantica resin extract. The objective of our study was to examine wound healing potential of Pistacia atlantica resin extract.

\section{Material and Method}

2.1. Animals and Experimental Protocol. Thirty-two female Wistar rats weighing $250 \pm 20 \mathrm{~g}$ at the burn time, from the Razi Institute of Iran, were housed in the animal unit (12-hour light/dark cycle, temperature approximately $23^{\circ} \mathrm{C}$ ) at least two weeks prior to the experiments. The rats were housed in individual cages with free access to water and food pellets. The rats were randomly divided into four groups and each rat got a number to perform the blindness of analyzers. After creating burn wounds, each group was dressed by a different extract dose of Pistacia atlantica resin for 14 days. At the 14th day, the animals were sacrificed and the wounds were separated to determine the healing grade by microscopic evaluation.

2.2. Burn Injury. The rats were anesthetized with intraperitoneal injection of ketamine $(50 \mathrm{mg} / \mathrm{kg})$ and xylazine $(5 \mathrm{mg} / \mathrm{kg})$. The dorsa of the animals were shaved and burn injury was induced by applying an aluminum plaque (1.5 $* 1.5 \mathrm{~cm}$ ) on the skin of the rats for 10 seconds which was heated to 100 degree centigrades in a dry oven, to create a deep dermal burn wound. All the procedure was done by the same person to minimize the bias of differences in the force the person applies. The reliability of this method in the production of full thickness burns has previously been validated by Koizumi et al. [24].

2.3. Plant Collection and Extract Preparation. The resin of Pistacia atlantica was collected from Zagros Mountains in Kurdistan province in October 2010. The plant was identified by Prof. M. R. Rahiminezhad, Herbarium Department of Biology, Faculty of Sciences, Isfahan, Iran, and voucher specimen (no. 2226) is deposited at the Department of Pharmacognosy, Isfahan University of Medical Sciences.

For quality control, Pistacia atlantica resin (50 g) was hydrodistilled (with $1.2 \mathrm{~L}$ water) in a clevenger-type apparatus for 4 hours according to British Pharmacopoeia guideline [25]. Pale yellow oil from the resin was obtained $(12 \% \mathrm{v} / \mathrm{w})$. One gr Carbopol 934 was added to $100 \mathrm{~mL}$ deionised water and was mixed and then triethanolamine was added drop by drop to the solution to obtain a desirable gel that would be used as a vehicle. To prepare the different concentrations of the ointment (resin extract), we added 5, 10, and 20 grams of the resin to 95,90 , and 80 grams of the vehicle to obtain $5 \%, 10 \%$, and $20 \%$ concentration ointment, respectively. The control group was treated only by the vehicle.

2.4. GC-MS Analysis. GC-MS analysis was performed on a Hewlett Packard 5792A mass selective detector coupled with a Hewlett Packard 6890 gas chromatograph, equipped with a HP-5MS capillary column $(30 \mathrm{~m} \times 0.25 \mathrm{~mm}$, film thickness $0.25 \mu \mathrm{m})$. The GC operating conditions were as follows: carrier gas, helium with a flow rate of $2 \mathrm{~mL} / \mathrm{min}$; column temperature, $60-280^{\circ} \mathrm{C}$ at $4^{\circ} \mathrm{C} / \mathrm{min}$; injector and detector temperatures, $280^{\circ} \mathrm{C}$; volume injected, $0.1 \mathrm{~mL}$ of the oil; and split ratio, 1:50. The MS operating parameters were as follows: ionization potential, $70 \mathrm{eV}$; ion source temperature, $250^{\circ} \mathrm{C}$; resolution, 1000 ; ionization current, $750 \mu \mathrm{A}$; and mass range, $35-425$.

Identification of the constituents was based on computer matching against the library spectra (Library Database Wiley $275 \mathrm{~L}$ ), their retention indices with reference to an n-alkane series in a temperature programmed run, interpreting their fragmentation pattern, and comparison of the mass spectra with those reported in the literature [26]. 
2.5. Treatment. The animals were divided into four groups. From the first day, wounds of the rats were dressed by $20 \mathrm{mg}$ of the Pistacia atlantica extract for each group daily. Group one (G1) was the control group in which the burn wounds were covered by an ointment base (vehicle) without any extract. Group 2 (G2), Group 3 (G3), and Group 4 (G4) received daily application of $5 \%, 10 \%$, and $20 \%$ prepared extracts, respectively.

2.6. Wound Size Assessment. The burn wounds were photographed after creating wound (first day) and at day 14, by the same instrument (Canon IXUS 200 IS Digital Camera) and settings, with fixed distance of camera from the wound and the same position of rats when imaging (Figure 1). Then the photos were analyzed by MATLAB R2009a software. Data from MATLAB software were pixels of wound image per pixels of one $\mathrm{cm}^{2}$. Differences between the wound size at the first day and also 14th day between groups and changes from the first day to 14th day were compared between groups. Also wound contraction $(=100-[$ (wound size on 14 th day/wound size on 1st day) *100]) was assessed [27].

2.7. Histological Assessment. After the 14th day, all the rats were scarified and the wounds were separated. All wound tissue specimens were fixed in $10 \%$ neutral-buffered formalin for at least $24 \mathrm{~h}$ at room temperature. After fixation, vertical sections to the anterior-posterior axis of the wound were dehydrated in graded ethanol, cleared in xylene, and embedded in paraffin. Four-micron-thick sections were mounted on glass slides, dewaxed, rehydrated to distilled water, and stained with hematoxylin and eosin. For histological evaluation, all slides were examined by two pathologists, without knowledge of the prior treatment, under a microscope from $\times 20$ to $\times 100$ magnifications. The histological score adopted in this study was performed according to the previous study concerning wound healing in experimental models. The criteria used as histological scores of wound healing are summarized in Table 1 [28]. Also the slides were examined to count the capillary count (capillary density). The presence of a capillary was defined according to the following criteria: (1) a lumen, (2) red blood cells and (3) an endothelial cell lining the lumen. The capillary counting for each slide was done in the $\times 400$ magnificent view in 4 different regions and the mean was reported [29].

2.8. Determination of bFGF, PDGF, and NO in Wounds Fluids. Three samples of wound fluid were collected using sterile nitrate-free absorbent paper strips placed on the edges of the wound for $10 \mathrm{~min}$, in order to measure bFGF, PDGF, and NO on the 5th day of the study. This method for the measurement has been validated for other sample types, particularly for tears [30-32]. For bFGF and PDGF measurement, protein elution from the Schirmer strips was performed by stirring the strips in $0.5 \mathrm{~mL}$ of buffer $(50 \mathrm{mM}$ Tris, $50 \mathrm{mM} \mathrm{NaCl}$, $0.05 \%$ Brij 35, pH 7.6) for at least $2 \mathrm{~h}$ at $+4^{\circ} \mathrm{C}$. For wound fluid $\mathrm{NO}$ determinations, filter paper was placed in $0.5 \mathrm{~mL}$ of distilled water [33]. The amount of bFGF and PDGF in wounds fluid was measured using enzyme-linked immunosorbent

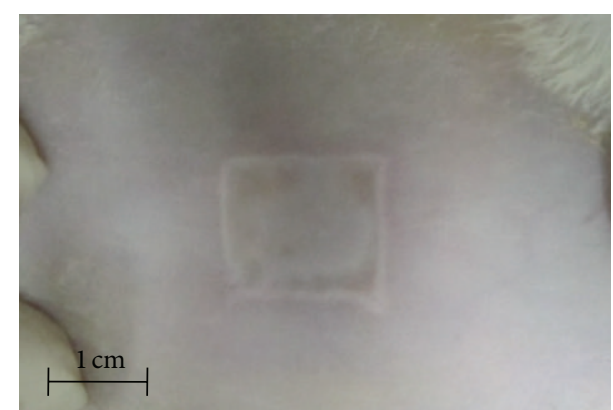

(a)

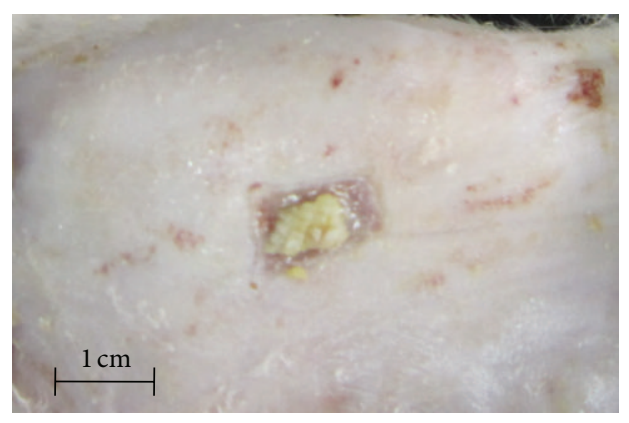

(b)

FIGURE 1: Macroscopic morphology of skin burn wound created by 10 -second application of $1.5 * 1.5$ aluminum plaque which was heated to 100 degree centigrade. (a) Macroscopic morphology of the wounds after 14-day treatment by Pistacia atlantica resin extract (b).

TABLE 1: Criteria to evaluate histological scores of wound healing for $\mathrm{H} \& \mathrm{E}$ staining.

\begin{tabular}{ll}
\hline Score & Criteria \\
\hline $1-3$ & $\begin{array}{l}\text { None to minimal cell accumulation. No granulation } \\
\text { tissue or epithelial travel. }\end{array}$ \\
\hline $4-6$ & $\begin{array}{l}\text { Thin, immature granulation tissue that is dominated by } \\
\text { inflammatory cells but has few fibroblasts, capillaries, } \\
\text { or collagen deposition. Minimal epithelial migration. }\end{array}$ \\
\hline & $\begin{array}{l}\text { Moderately thick granulation tissue can range from } \\
\text { being dominated by inflammatory cells to more } \\
\text { fibroblasts and collagen deposition. Extensive } \\
\text { neovascularization. Epithelium can range from } \\
\text { minimal to moderate migration. }\end{array}$ \\
\hline $9-12$ & $\begin{array}{l}\text { Thick, vascular granulation tissue dominated by } \\
\text { fibroblasts and extensive collagen deposition. } \\
\text { Epithelium partially to completely covering the wound. }\end{array}$ \\
\hline
\end{tabular}

assay by available reagents and recombinant standards (R\&D Systems, Minneapolis, MN) according to the manufacturer's instruction in 5th day samples. The total NO level of wound fluid was measured using the Griess assay after conversion of $\mathrm{NO}_{3}$ to $\mathrm{NO}_{2}$ with the $\mathrm{NO}_{3}$ reductase enzyme as described previously [34].

2.9. Statistical Analysis. All data are expressed as the mean \pm the standard deviation (mean $\pm \mathrm{SD}$ ). A statistical software package, SPSS (version 16), was used to perform statistical analysis. The data were tested for normality and homogeneity 
of variance. Data were analyzed by analysis of variance (ANOVA), followed by a post hoc multiple comparison. For the histological results, statistical analysis was performed using Kruskal-Wallis test. Statistical significance was accepted at $P<0.05$.

\section{Results}

The Pistacia atlantica resin composition was identified and is reported in Table 2. alpha-Pinene (46.57\%) was the main constituent followed by beta-pinene $(9.08 \%)$, trans-verbenol (6.41\%), sabinene (4.49\%), and trans-pinocarveol (4.05\%).

At the first day of experiment, there was no significant difference in the mean weight of groups (mean weight of all the animals was $194.37 \pm 19.37$ and the $P$ value of comparing the groups was calculated as 0.198). As it is shown in Table 3, there was no significant difference in the wound size in the first day and also 14th day. The wound size decreases in the G1, G2, G3, and G4 were $0.98 \pm 0.35,1.43 \pm 0.39,1.30 \pm 0.40$ and $1.09 \pm 0.34$, respectively and the $P$ value calculated for comparing differences was 0.103 . Wound contraction for G1, G2, G3, and G4 was $41.98 \pm 15.93,58.17 \pm 15.08,46.52 \pm 16.03$ and $43.50 \pm 10.23$ percent, respectively $(P=0.091)$.

Table 4 shows that there was no significant difference between groups in the rate of wound healing score determined by microscopic analysis of wounds. The capillary count analysis showed that there is a significant difference between groups and G2 and G3 had a higher capillary count (Table 4). G4 had a lower capillary count than G2 and G3 but it was not statistically significant $(0.753$ and 0.680 , resp.). Figure 2 is showing the histopathology of the wounds in different groups of the study after 14 days.

The concentration of $\mathrm{NO}(\mu \mathrm{mol} / \mathrm{mL})$ (mean \pm standard error) in the burning wound fluids of G1, G2, G3, and G4 was $3.20 \pm 0.97,2.92 \pm 0.95,5.18 \pm 0.61$, and $3.68 \pm 0.69$, respectively. The differences were not statistically significant $(P=0.232)$.

The concentration of bFGF and PDGF in the wound fluids is shown in Table 5. There is a significant difference in the level of PDGF concentration in the wound fluids between groups $(P=0.034)$. Also differences between groups are statistically significant in the case of bFGF $(P=0.007)$. Differences between G1 and the two groups of G2 and G3 are statistically significant ( $P$ value of 0.043 and 0.017 , resp.).

\section{Discussion}

The complex process of wound healing is regulated by an equally complex signaling network involving numerous growth factors, cytokines, and chemokines $[14,15]$. The aim of our study was to investigate the effect of Pistacia atlantica resin extract on burning wound healing because of its wide traditional use in Kurdistan of Iran to cure wounds especially burning wounds. We evaluate morphological, histopatholog$\mathrm{ical}$, and biochemical parameters for wound healing potential assessment of Pistacia atlantica resin extracts in burned rats.

In this study, the wound size analysis results showed that although there were no significant differences between
TABle 2: Composition of Pistacia atlantica resin oil.

\begin{tabular}{|c|c|c|c|}
\hline No. & Compound & $\mathrm{RI}^{*}$ & $\%^{* *}$ \\
\hline 1 & Tetramethylcyclopentene & 839 & 0.23 \\
\hline 2 & alpha-Pinene & 942 & 46.58 \\
\hline 3 & Camphene & 964 & 2.03 \\
\hline 4 & Verbenene & 967 & 1.73 \\
\hline 5 & Sabinene & 982 & 4.49 \\
\hline 6 & beta-Pinene & 988 & 9.08 \\
\hline 7 & Myrcene & 995 & 0.19 \\
\hline 8 & alpha-Phellandrene & 1009 & 0.49 \\
\hline 9 & delta-3-Carene & 1031 & 1.58 \\
\hline 10 & alpha-Terpinene & 1017 & 0.28 \\
\hline 11 & Methane & 1026 & 0.20 \\
\hline 12 & Para cymene & 1025 & 1.49 \\
\hline 13 & Limonene & 1029 & 3.40 \\
\hline 14 & Cineole & 1031 & 0.38 \\
\hline 15 & trans-beta-Ocimene & 1042 & 1.08 \\
\hline 16 & gamma-Terpinene & 1060 & 0.53 \\
\hline 17 & cis-Sabinene hydrate & 1070 & 0.38 \\
\hline 18 & Linalool & 1097 & 1.33 \\
\hline 19 & alpha-Campholene & 1128 & 1.28 \\
\hline 20 & trans-Pinocarveol & 1143 & 4.05 \\
\hline 21 & cis-Verbenol & 1145 & 1.14 \\
\hline 22 & trans-Verbenol & 1151 & 6.41 \\
\hline 23 & Pinocarvone & 1164 & 0.30 \\
\hline 24 & Terpineol-4 & 1179 & 1.01 \\
\hline 25 & alpha-Terpineol & 1191 & 0.78 \\
\hline 26 & Myrtenol & 1196 & 1.73 \\
\hline 27 & trans-Carveol & 1219 & 0.57 \\
\hline 28 & Chrysanthemyl acetate & 1261 & 0.23 \\
\hline 29 & Bornyl acetate & 1284 & 0.38 \\
\hline 30 & alpha-Terpinyl acetate & 1348 & 0.32 \\
\hline
\end{tabular}

${ }^{*}$ Retention indices on HP-5MS capillary column.

${ }^{* *}$ Calculated from TIC data.

groups but in all groups treated by resin extract, decreasing in wound sizes was more than G1. Also wound contraction analysis had the same results and showed that although there is no significant difference between groups, all groups had higher percentages of contraction than the Gl. Wound healing scoring showed that the healing rates of groups treated by resin extract (G2, G3 and G4) were higher than G1 but statistically not significant. Since nearly all groups got a score lower than $50 \%$ of our scoring system, conducting similar studies in a study time more than 14 days and also using larger sample sizes are recommended. It is reported that myofibroblasts are cells specialized in wound contraction and synthesis of new extracellular matrix. Normal wound myofibroblasts contribute to angiogenesis during wound healing that is mediated by increase in tissue inhibitor of metalloproteinase [35].

Our results showed that capillary count in groups treated with Pistacia atlantica extract is higher than that of the G1 and differences of G1 with G2 and G3 were statistically 
TABLE 3: Wound size $\left(\mathrm{cm}_{2}\right)$ analysis of the studied group in first and 14th days of the study.

\begin{tabular}{|c|c|c|c|}
\hline & $\begin{array}{c}\text { First day } \\
\text { mean } \pm \mathrm{SD}(n)\end{array}$ & $\begin{array}{c}14 \text { th day } \\
\text { mean } \pm \text { SD }(n)\end{array}$ & $\begin{array}{c}\text { Wound contraction }^{\wedge} \\
\text { mean } \pm \mathrm{SD}(n)\end{array}$ \\
\hline Control group & $2.36 \pm 0.18(8)$ & $1.37 \pm 0.41(8)$ & $41.98 \pm 15.93(8)$ \\
\hline Group treated by $5 \%$ EC & $2.48 \pm 0.22(8)$ & $1.05 \pm 0.48(8)$ & $58.17 \pm 15.08(8)$ \\
\hline Group treated by $10 \%$ EC & $2.30 \pm 0.31(8)$ & $1.00 \pm 0.43(7)$ & $46.52 \pm 16.03(7)$ \\
\hline Group treated by $20 \%$ EC & $2.47 \pm 0.24(8)$ & $1.38 \pm 0.15(8)$ & $43.50 \pm 10.23(8)$ \\
\hline${ }^{\dagger} P$ value & 0.389 & 0.133 & 0.091 \\
\hline
\end{tabular}

EC: extract concentration. ${ }^{\wedge}$ Data are given as percentages, ${ }^{\dagger}$ by comparison of all groups (ANOVA test). $n$ : number of animals.

TABLE 4: Wound healing score and capillary count analysis of studied groups after $\mathrm{H} \& \mathrm{E}$ staining.

\begin{tabular}{lccc}
\hline Groups & $\begin{array}{c}\text { Wound healing } \\
\text { score }\end{array}$ & Capillary count & $P$ value $^{\dagger}$ \\
\hline $\begin{array}{l}\text { Control group } \\
\text { Group treated by }\end{array}$ & $3.28 \pm 0.28$ & $09.28 \pm 1.01$ & \\
$\begin{array}{l}5 \% \text { EC } \\
\text { Group treated by }\end{array}$ & $4.20 \pm 0.58$ & $15.12 \pm 1.74$ & $0.042^{*}$ \\
$\begin{array}{l}\text { 10\% EC } \\
\text { Group treated by }\end{array}$ & $3.40 \pm 1.77$ & $15.37 \pm 1.23$ & $0.032^{*}$ \\
$\begin{array}{l}\text { 20\% EC } \\
{ }^{\dagger} P \text { value }\end{array}$ & 0.066 & $13.12 \pm 1.55$ & 0.274 \\
\hline
\end{tabular}

EC: extract concentration. Data are given as mean \pm standard error, ${ }^{\dagger}$ comparison of G1 with other groups for capillary count analysis, ${ }^{*}$ significantly different from the control group, ${ }^{* *}$ statistically significant difference, ${ }^{\dagger \dagger}$ by comparison of all groups (Kruskal-Wallis test).

significant. Although differences of G4 with G2 and G3 were not statistically significant, the capillary count for G4 was lower than them. Our results showed that higher doses of Pistacia atlantica resin extract are associated with lower angiogenesis and this is consistent with other studies that revealed that mastic oil from Pistacia lentiscus has a dose-dependent effect on vascular endothelial growth factor (VEGF) concentration and also angiogenesis. Loutrari et al. showed that in higher doses of mastic oil extraction from Pistacia lentiscus, angiogenesis will reduce. Their results showed that VEGF concentration in groups treated by low dose of extract is higher than in the group using vehicle without any extract. But in higher doses, VEGF is lower even than the group treated by vehicle [36]. Djerrou et al. revealed that Pistacia lentiscus virgin fatty oil significantly promotes wound contraction and reduces epithelialization period in rabbit model [37]. Another study showed that Pistacia lentiscus fatty oil improves the burn wound healing properties of honey when mixed in rabbit model [38].

Analysis of NO, bFGF and PDGF concentration in wound fluids on the 5th day of study showed that the concentration of NO in wound fluid was not significantly different between groups. G1 had lower PDGF concentration than all other groups and the difference with G3 was statistically significant. The bFGF concentration in groups treated by low dose of extract was higher than control group and the differences with G2 and G3 were statistically significant.
The burnt wound healing is a complex process and requires a well-coordinated collaboration of different tissues and cells. Angiogenesis has an important role in the healing process of skin burns. The angiogenesis starts fast and about three days after producing the burn, endothelial precursor cells will be identified. The density of the vessels will grow about two weeks. After that, they reduce progressively while the tissue of granulation become mature [39]. This may be the explanation for our results that showed significant differences between groups when considering capillary count, PDGF, and bFGF but no significant differences when we compared wound healing scores and wound sizes. As we mentioned previously, healing score that all groups received after 14 days was nearly lower than $50 \%$ of the total score and conducting studies with duration of more than 14 days is recommended.

It has been shown that reducing $\mathrm{NO}$ production by NO synthase knockout mice impairs wound healing [40]. Furthermore, NO has a regulatory role in vascular endothelial growth factor (VEGF) through wound healing process. VEGF is a key angiogenic molecule with an important role in vascular permeability which implies the importance of VEGF in wound healing [41]. Also NO is effective in proliferations of vascular smooth muscle cells by PDGF as a potent smooth muscle chemoattractant and mitogen $[42,43]$. bFGF is an important inducer of angiogenesis, in in vitro angiogenesis models of endothelial cells. bFGF could induce angiogenesis, and this action was linked to VEGF production through the activation of endothelial nitric oxide synthase in endothelial cells [44].

The burn wound represents a susceptible site for colonization of organisms with endogenous and exogenous origin [45]. Some studies showed that Pistacia atlantica extracts have considerable antimicrobial activity, specifically antifungal effect, and also are effective in reducing and scavenging the superoxide anions in vitro $[2,46]$. An in vitro study evaluation of the biological activity of Cedrus libani (Pinaceae) - in which the main constituents of the cones ethanol extract are $\alpha$-pinene (51.0\%) and $\beta$-myrcene (13.0\%) - against Herpes simplex virus type 1 (HSV-1) showed an interesting antiviral activity [47]. Some studies have reported an antibacterial effect for $\beta$-pinene and $\alpha$-pinene. It has been proved that $\alpha$-pinene has an interesting antibacterial effect $[2,48]$. Our results showed that the main constituent of Pistacia atlantica was $\alpha$-pinene ( $46.57 \%)$, so its antibacterial effect can be another reason of wound healing effect of this plant. 


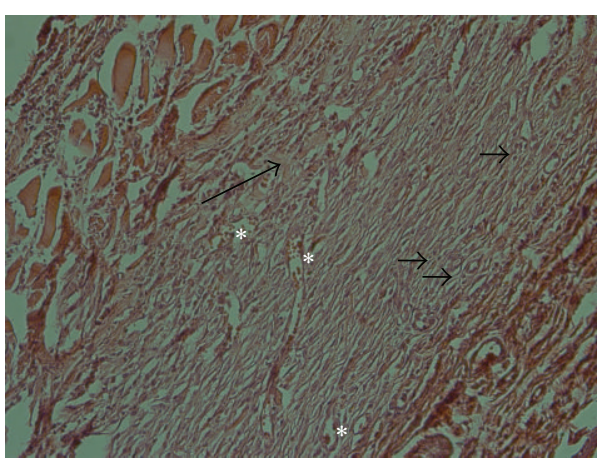

(a)

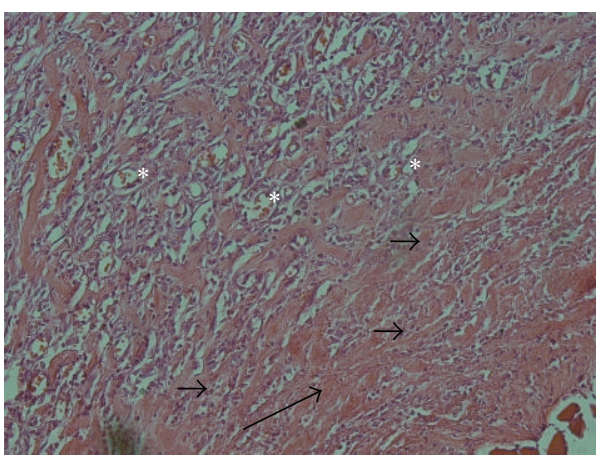

(c)

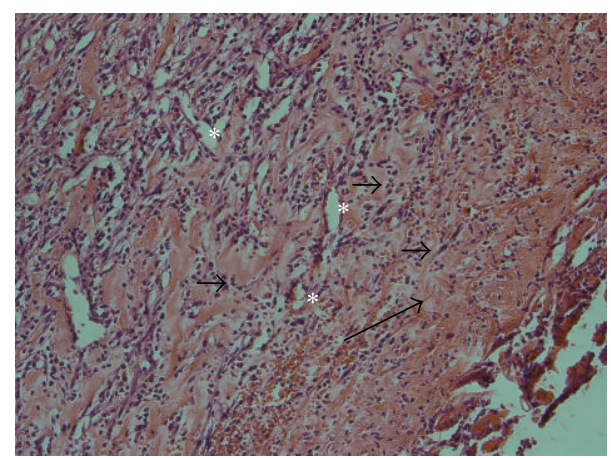

(b)

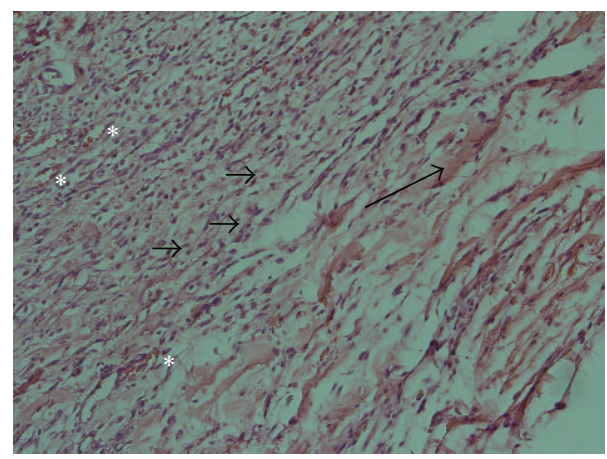

(d)

Figure 2: Histopathology of burn wounds at day 14 stained with H\&E (200x). (a) Control group. (b) Group treated by 5\% extract concentration. (c) Group treated by $10 \%$ extract concentration. (d) Group treated by $20 \%$ extract concentration. Stars show capillaries. Small arrows show fibroblasts. Long arrows show granulation.

TABLE 5: Evaluation and analysis of bFGF, PDGF and NO concentrations in the wounds fluid in 5th day of the study.

\begin{tabular}{|c|c|c|c|c|c|}
\hline Groups & $\begin{array}{c}\mathrm{bFGF}^{\wedge} \\
\text { mean } \pm \mathrm{SD}(n)\end{array}$ & $P$ value $^{\dagger}$ & $\begin{array}{c}\mathrm{PDGF}^{\wedge} \\
\text { mean } \pm \mathrm{SD}(n)\end{array}$ & $P$ value $^{\dagger}$ & $\begin{array}{c}\mathrm{NO}^{M} \\
\text { mean } \pm \mathrm{SD}(n)\end{array}$ \\
\hline Control group & $50.60 \pm 0.43(7)$ & & $18.64 \pm 1.70(6)$ & & $3.20 \pm 0.97(8)$ \\
\hline Group treated by $5 \%$ EC & $52.60 \pm 1.71(8)$ & $0.043^{*}$ & $24.58 \pm 7.05(8)$ & 0.255 & $2.92 \pm 0.95(7)$ \\
\hline Group treated by $10 \%$ EC & $52.90 \pm 1.79(8)$ & $0.017^{*}$ & $28.89 \pm 4.78(7)$ & $0.019^{*}$ & $5.18 \pm 0.61(8)$ \\
\hline Group treated by $20 \%$ EC & $51.17 \pm 1.00(8)$ & 0.589 & $24.70 \pm 6.96(8)$ & 0.240 & $3.68 \pm 0.69(8)$ \\
\hline${ }^{\dagger \dagger} P$ value & $0.007^{* *}$ & & $0.034^{* *}$ & & 0.232 \\
\hline
\end{tabular}

EC: extract concentration. Data is given as mean $\pm \mathrm{SD},{ }^{\dagger}$ comparison of G1 with other groups, ${ }^{\wedge}$ concentration $(\mathrm{pg} / \mathrm{mL}),{ }^{\wedge} \mathrm{concentration}(\mu \mathrm{mol} / \mathrm{mL})$, ${ }^{*}$ significantly different from the control group, ${ }^{* *}$ statistically significant difference, ${ }^{\dagger \dagger}$ by comparison of all groups (ANOVA test). $n$ : number of animals.

\section{Conclusion}

Our results showed that Pistacia atlantica resin may be useful in the treatment of burning wounds by increasing the concentration of bFGF and PDGF and also by increasing the angiogenesis. Plants are not only cheap but also safe, so they can be used widely to treat wounds. Interestingly our results showed that the effect of Pistacia atlantica resin on burning wound healing (after 14 days of treatment by the plant) is dose-dependent and in higher doses has reverse effect and lower healing will occur. We suggest that repeating the same study with larger sample size, longer period of time (more than 14 days), and also more divided doses will be more informative.

\section{Acknowledgments}

The authors thank the staff of the Physiology Research Centre. They are also grateful to Mrs. Khadije Fathi and Mr Fayegh Nazari for their kind and detailed explanation of the method of treating burning wounds in the village they are living in.

\section{References}

[1] S. Sharafzadeh and O. Alizadeh, "Some medicinal plants cultivated in Iran," Journal of Applied Pharmaceutical Science, vol. 2, no. 1, pp. 134-137, 2012.

[2] M. Tohidi, M. Khayami, V. Nejati, and H. Meftahizade, "Evaluation of antibacterial activity and wound healing of Pistacia 
atlantica and Pistacia khinjuk," Journal of Medicinal Plant Research, vol. 5, no. 17, pp. 4310-4314, 2011.

[3] A. Delazar, R. G. Reid, and S. D. Sarker, "GC-MS analysis of the essential oil from the oleoresin of Pistacia atlantica var. mutica," Chemistry of Natural Compounds, vol. 40, no. 1, pp. 24-27, 2004.

[4] A. Daneshrad and Y. Aynehchi, "Chemical studies of the oil from pistacia nuts growing wild in iran," Journal of the American Oil Chemists' Society, vol. 57, no. 8, pp. 248-249, 1980.

[5] M. Peck, J. Molnar, and D. Swart, "A global plan for burn prevention and care," Bulletin of the World Health Organization, vol. 87, no. 10, pp. 802-803, 2009.

[6] F. Wu, D. Bian, Y. Xia et al., "Identification of major active ingredients responsible for burn wound healing of Centella asiatica herbs," Evidence-Based Complementary and Alternative Medicine, vol. 2012, Article ID 848093, 13 pages, 2012.

[7] M. G. Schwacha, B. M. Thobe, T. Daniel, and W. J. Hubbard, "Impact of thermal injury on wound infiltration and the dermal inflammatory response," Journal of Surgical Research, vol. 158, no. 1, pp. 112-120, 2010.

[8] M. B. Witte and A. Barbul, "General principles of wound healing," Surgical Clinics of North America, vol. 77, no. 3, pp. 509-528, 1997.

[9] Y. Nakajima, Y. Nakano, S. Fuwano et al., "Effects of three types of Japanese honey on full-thickness wound in mice," Evidence-Based Complementary and Alternative Medicine, vol. 2013, Article ID 504537, 11 pages, 2013.

[10] A. Neub, P. Houdek, U. Ohnemus, I. Moll, and J. M. Brandner, "Biphasic regulation of AP-1 subunits during human epidermal wound healing," Journal of Investigative Dermatology, vol. 127, no. 10, pp. 2453-2462, 2007.

[11] N. S. Al-Waili, K. Salom, and A. A. Al-Ghamdi, "Honey for wound healing, ulcers, and burns; data supporting its use in clinical practice," TheScientific WorldJournal, vol.11, pp. 766-787, 2011.

[12] B. S. Nayak and L. M. Pinto Pereira, "Catharanthus roseus flower extract has wound-healing activity in Sprague Dawley rats," BMC Complementary and Alternative Medicine, vol. 6, article 41, 2006.

[13] S. Rawat and A. Gupta, "Development and study of wound healing activity of an ayurvedic formulation," Asian Journal of Pharmaceutical Sciences, vol. 1, no. 1, pp. 26-28, 2011.

[14] S. Barrientos, O. Stojadinovic, M. S. Golinko, H. Brem, and M. Tomic-Canic, "Growth factors and cytokines in wound healing," Wound Repair and Regeneration, vol. 16, no. 5, pp. 585601, 2008.

[15] S. E. Lynch, R. B. Colvin, and H. N. Antoniades, "Growth factors in wound healing. Single and synergistic effects on partial thickness porcine skin wounds," Journal of Clinical Investigation, vol. 84, no. 2, pp. 640-646, 1989.

[16] J. C. Ansel, J. P. Tiesman, J. E. Olerud et al., "Human keratinocytes are a major source of cutaneous platelet-derived growth factor," Journal of Clinical Investigation, vol. 92, no. 2, pp. 671-678, 1993.

[17] G. S. Ashcroft, M. A. Horan, and M. W. J. Ferguson, "The effects of ageing on wound healing: immunolocalisation of growth factors and their receptors in a murine incisional model," Journal of Anatomy, vol. 190, no. 3, pp. 351-365, 1997.

[18] G. F. Pierce, T. A. Mustoe, J. Lingelbach, V. R. Masakowski, P. Gramates, and T. F. Deuel, "Transforming growth factor $\beta$ reverses the glucocorticoid-induced wound-healing deficit in rats: possible regulation in macrophages by platelet-derived growth factor," Proceedings of the National Academy of Sciences of the United States of America, vol. 86, no. 7, pp. 2229-2233, 1989.

[19] R. E. Friesel and T. Maciag, "Molecular mechanisms of angiogenesis: fibroblast growth factor signal transduction," FASEB Journal, vol. 9, no. 10, pp. 919-925, 1995.

[20] A. S. Sahib, F. H. Al-Jawad, and A. A. Alkaisy, "Effect of antioxidants on the incidence of wound infection in burn patients," Annals of Burns and Fire Disasters, vol. 23, no. 4, pp. 199-205, 2010.

[21] A. Bishop, "Role of oxygen in wound healing," Journal of Wound Care, vol. 17, no. 9, pp. 399-402, 2008.

[22] J. D. Luo and A. F. Chen, "Nitric oxide: a newly discovered function on wound healing," Acta Pharmacologica Sinica, vol. 26, no. 3, pp. 259-264, 2005.

[23] A. Soneja, M. Drews, and T. Malinski, "Role of nitric oxide, nitroxidative and oxidative stress in wound healing," Pharmacological Reports, vol. 57, pp. 108-119, 2005.

[24] T. Koizumi, H. Goto, H. Tanaka, Y. Yamaguchi, and S. Shimazaki, "Lecithinized superoxide dismutase suppresses free radical substrates during the early phase of burn care in rats," Journal of Burn Care and Research, vol. 30, no. 2, pp. 321-328, 2009.

[25] British Pharmacopoeia, vol. 2, HMSO, London, UK, 1998.

[26] R. P. Adams, Identification of Essential Oil Components by Gas Chromatography/Mass Spectrometry, Allured Publishing Corporation, 2007.

[27] R. Thakur, N. Jain, R. Pathak, and S. S. Sandhu, "Practices in wound healing studies of plants," Evidence-Based Complementary and Alternative Medicine, vol. 2011, Article ID 438056, 17 pages, 2011.

[28] D. G. Greenhalgh, K. H. Sprugel, M. J. Murray, and R. Ross, "PDGF and FGF stimulate wound healing in the genetically diabetic mouse," American Journal of Pathology, vol. 136, no. 6, pp. 1235-1246, 1990.

[29] W. K. Ward, M. J. Quinn, M. D. Wood, K. L. Tiekotter, S. Pidikiti, and J. A. Gallagher, "Vascularizing the tissue surrounding a model biosensor: how localized is the effect of a subcutaneous infusion of vascular endothelial growth factor (VEGF)?" Biosensors and Bioelectronics, vol. 19, no. 3, pp. 155-163, 2003.

[30] C. D. Barro, J. P. Romanet, A. Fdili, M. Guillot, and F. Morel, "Gelatinase concentration in tears of corneal-grafted patients," Current Eye Research, vol. 17, no. 2, pp. 174-182, 1998.

[31] M. Muller, C. Trocme, B. Lardy, F. Morel, S. Halimi, and P. Y. Benhamou, "Matrix metalloproteinases and diabetic foot ulcers: the ratio of MMP-1 to TIMP-1 is a predictor of wound healing," Diabetic Medicine, vol. 25, no. 4, pp. 419-426, 2008.

[32] E. Zandifar, S. Sohrabi Beheshti, A. Zandifar, and H. S. Javanmard, "The effect of captopril on impaired wound healing in experimental diabetes," International Journal of Endocrinology, vol. 2012, Article ID 785247, 6 pages, 2012.

[33] J. V. Boykin Jr. and C. Baylis, "Hyperbaric oxygen therapy mediates increased nitric oxide production associated with wound healing: a preliminary study," Advances in Skin \& Wound Care, vol. 20, no. 7, pp. 382-388, 2007.

[34] S. Haghjooyjavanmard, M. Nematbakhsh, A. Monajemi, and M. Soleimani, "von Willebrand factor, C-reactive protein, nitric oxide, and vascular endothelial growth factor in a dietary reversal model of hypercholesterolemia in rabbit," Biomedical papers of the Medical Faculty of the University Palacký, Olomouc, Czechoslovakia, vol. 152, no. 1, pp. 91-95, 2008. 
[35] D. Mayrand, A. Laforce-Lavoie, S. Larochelle et al., "Angiogenic properties of myofibroblasts isolated from normal human skin wounds," Angiogenesis, vol. 15, no. 2, pp. 199-212, 2012.

[36] H. Loutrari, S. Magkouta, A. Pyriochou et al., "Mastic oil from Pistacia lentiscus var. chia inhibits growth and survival of human K562 leukemia cells and attenuates angiogenesis," Nutrition and Cancer, vol. 55, no. 1, pp. 86-93, 2006.

[37] Z. Djerrou, Z. Maameri, Y. Hamdi-Pacha et al., "Effect of virgin fatty oil of Pistacia lentiscus on experimental burn wound's healing in rabbits," African Journal of Traditional, Complementary and Alternative Medicines, vol. 7, no. 3, pp. 258$263,2010$.

[38] Z. Maameri, K. Beroual, Z. Djerrou et al., "Preliminary study to assess cicatrizing activity of honey and Pistacia lentiscus fatty oil mixture on experimental burns in rabbits," International Journal of Medicinal and Aromatic Plants, vol. 2, no. 3, pp. 476-480, 2012.

[39] C. J. Busuioc, G. Mogoşanu, F. C. Popescu, I. Lascar, H. Pârvanescu, and L. Mogoanta, "Phases of the cutaneous angiogenesis process in experimental third-degree skin burns: histological and immunohistochemical study," Romanian Journal of Morphology and Embryology, vol. 54, no. 1, pp. 163-171, 2012.

[40] D. Most, D. T. Efron, H. P. Shi, U. S. Tantry, and A. Barbul, "Characterization of incisional wound healing in inducible nitric oxide synthase knockout mice," Surgery, vol. 132, no. 5, pp. 866-876, 2002.

[41] T. A. Wilgus and L. A. Dipietro, "Complex roles for VEGF in dermal wound healing," Journal of Investigative Dermatology, vol. 132, no. 2, pp. 493-494, 2012.

[42] J. Huang, L. S. Li, D. L. Yang, Q. H. Gong, J. Deng, and X. N. Huang, "Inhibitory effect of ginsenoside Rg1 on vascular smooth muscle cell proliferation induced by PDGF-BB is involved in nitric oxide formation," Evidence-Based Complementary and Alternative Medicine, vol. 2012, Article ID 314395, 7 pages, 2012.

[43] G. A. A. Ferns, E. W. Raines, K. H. Sprugel, A. S. Motani, M. A. Reidy, and R. Ross, "Inhibition of neointimal smooth muscle accumulation after angioplasty by an antibody to PDGF," Science, vol. 253, no. 5024, pp. 1129-1132, 1991.

[44] Q. Lu, C. Wang, R. Pan et al., "Histamine synergistically promotes bFGF-induced angiogenesis by enhancing VEGF production via $\mathrm{H} 1$ receptor," Journal of Cellular Biochemistry, vol. 114, no. 5, pp. 1009-1019, 2013.

[45] A. R. Qader and J. A. Muhamad, "Nosocomial infection in sulaimani burn hospital, IRAQ," Annals of Burns and Fire Disasters, vol. 23, no. 4, pp. 177-181, 2010.

[46] N. Benhammou, F. A. Bekkara, and T. K. Panovska, "Antioxidant and antimicrobial activities of the Pistacia lentiscus and Pistacia atlantica extracts," African Journal of Pharmacy and Pharmacology, vol. 2, no. 2, pp. 022-028, 2008.

[47] B. Adorjan, Biological Properties of Essential Oils, Uniwien, 2010.

[48] A. M. Leite, E. D. O. Lima, E. L. De Souza, M. D. F. F. M. Diniz, V. N. Trajano, and I. A. De Medeiros, "Inhibitory effect of $\beta$-pinene, $\alpha$-pinene and eugenol on the growth of potential infectious endocarditis causing Gram-positive bacteria," Revista Brasileira de Ciencias Farmaceuticas, vol. 43, no. 1, pp. 121-126, 2007. 


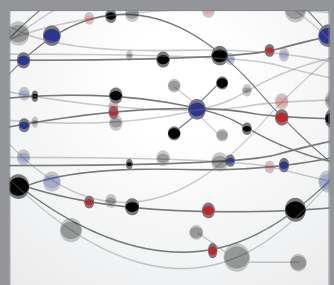

The Scientific World Journal
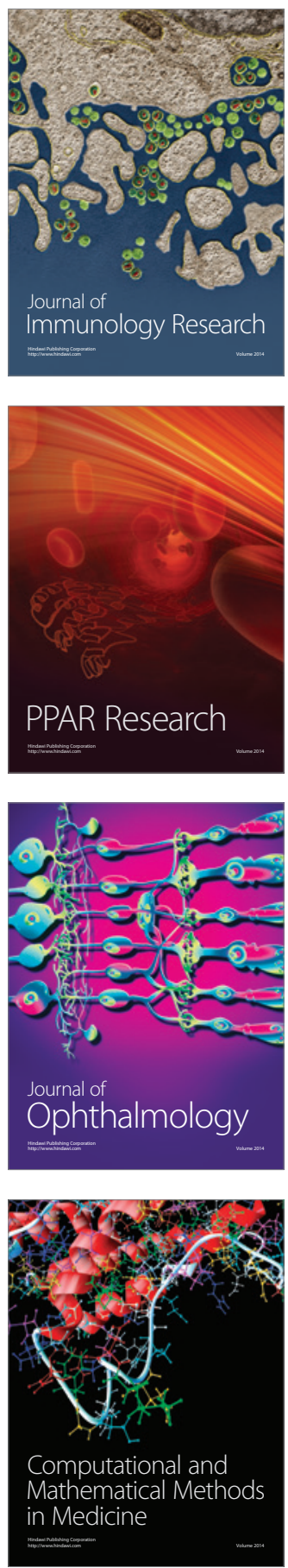

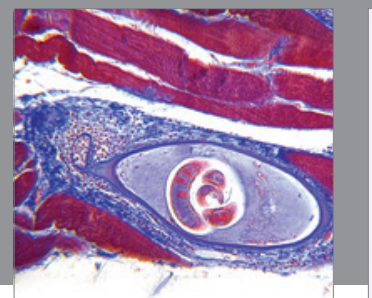

Gastroenterology

Research and Practice
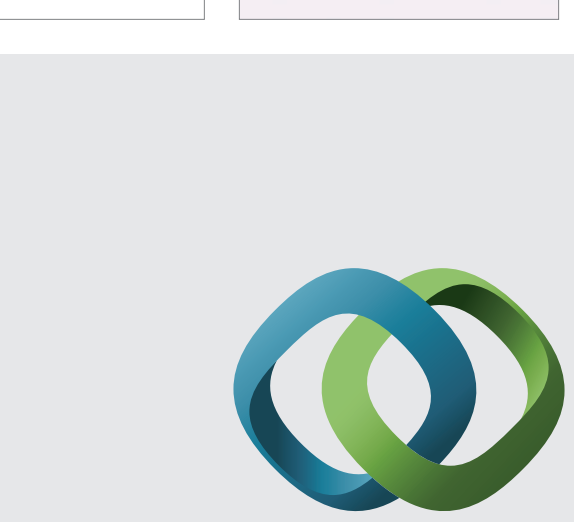

\section{Hindawi}

Submit your manuscripts at

http://www.hindawi.com
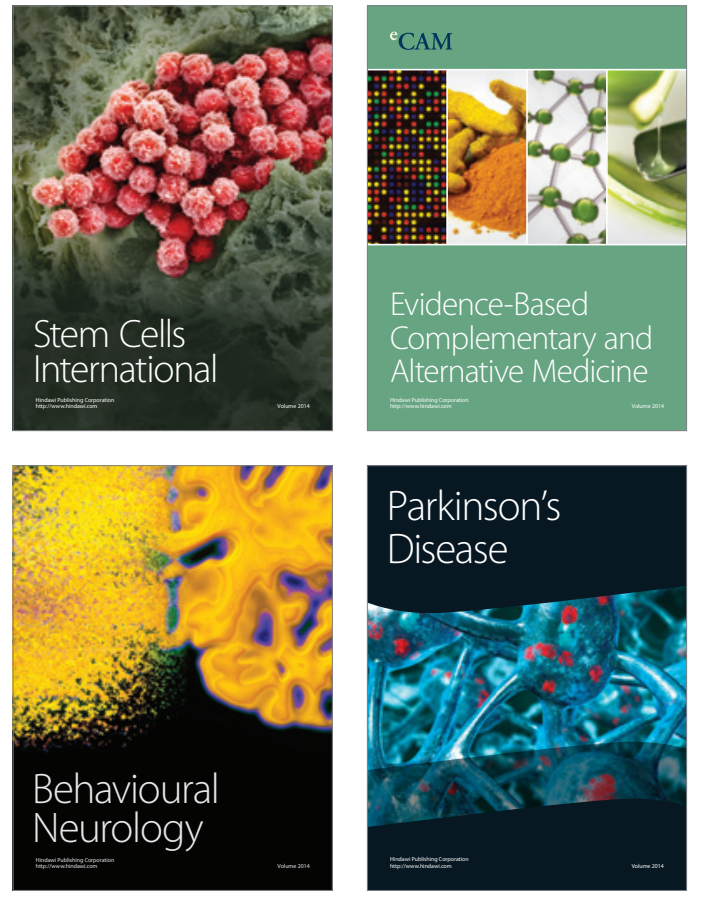
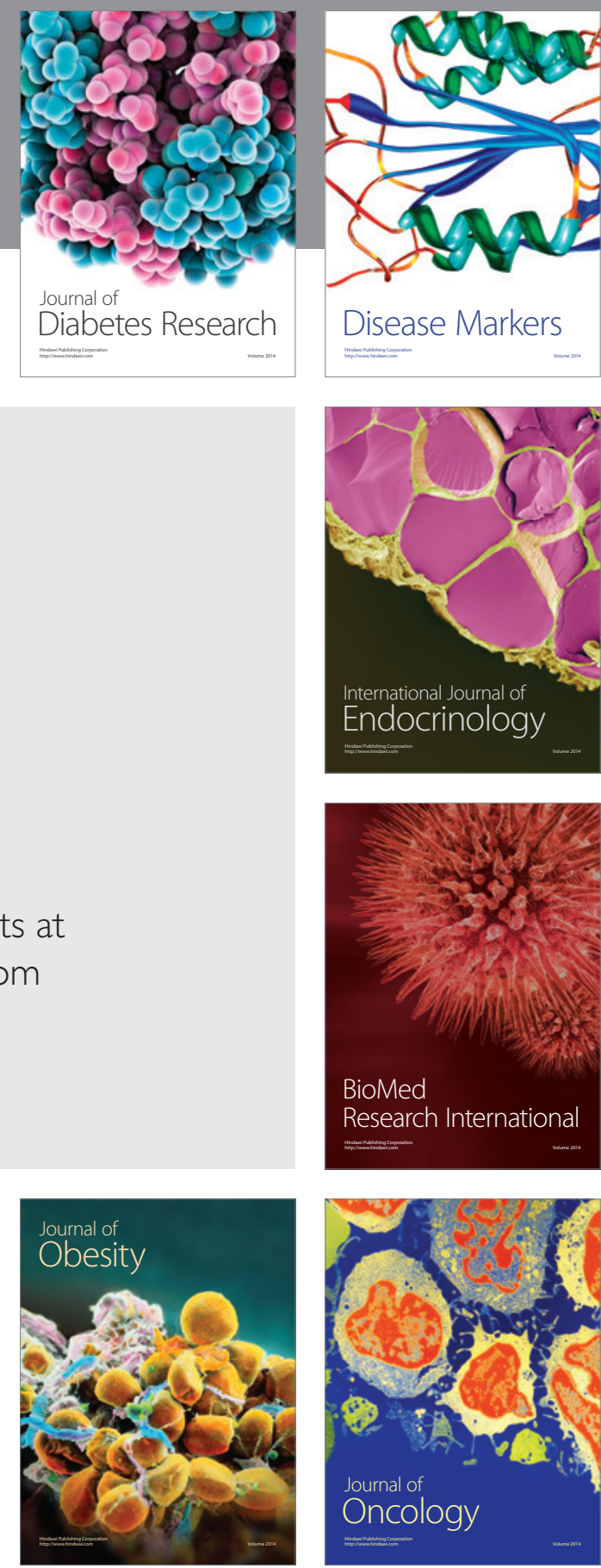

Disease Markers
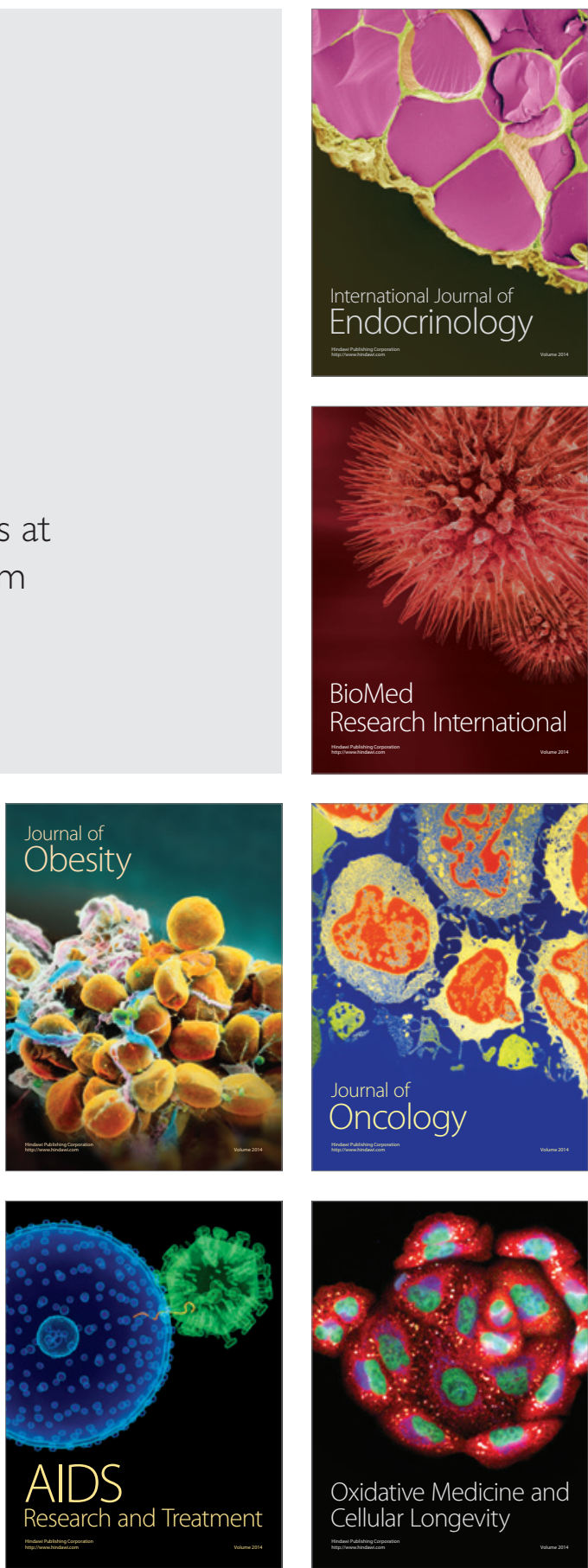